Original article

\title{
Virtual reality applications toward medical field
}

\author{
Mohd Javaid*, Abid Haleem \\ Department of Mechanical Engineering, Jamia Millia Islamia, New Delhi, India
}

\section{A R T I C L E I N F O}

\section{Keywords:}

3D virtual data

Virtual reality (VR)

Medical

Training

Diagnosis

Treatment

\begin{abstract}
A B S T R A C T
Background/objectives: Virtual Reality (VR) is a developing technology, which seems to have extensive applications in different areas such as entertainment, sports, gaming and simulation. In the current scenario, due to Computer-generated imagery and content aim at simulating a real presence through senses capability, it has functional applications in the medical field. So, there are requirements to study its applicability in the medical field.

Methods: Relevant papers on VR in the context of the medical field are identified and studied. This paper is a literature review based analysis, where we are trying to find how this technology is going to solve a medicalrelated problem in saving the life of the patient and what are the significant applications.

Results: VR provides a simulated environment to interact with the 3D world. Medical professionals are developing and implementing this technology for training, diagnosis and virtual treatment during a critical situation. The study sees that there is good potential for VR in the medical field. We also studied the processes involved in implementing this technology in the medical field. Finally, this paper identifies fourteen major applications of VR in the medical field with description. This technology is helping to create quality healthcare services during complicated cases.

Conclusions: VR is used effectively for better surgical technique. It creates detailed virtual models of a patient's anatomy. It helps physicians to effectively move around and view virtual 3D images from different angles. This technology is currently applied in cardiology and Neurology for monitoring and improves patient outcomes. It plays a significant role to help physician related to trauma and other fractures. VR is an emerging technology which can also be used in hospitals and clinics for rehabilitation \& training approaches. The applications of this technology are in virtual guides and to fulfil different other virtual goals in the medical field. It seems like an efficient technology to teach body fitness and help create a positive impact on doctors and the patient. This technology leads to creative and exciting discoveries in the medical field.
\end{abstract}

\section{Introduction}

Today virtual reality (VR) is getting famous due to its vast applications in different fields. This technology provides a better opportunity for 3D visualization during teaching purpose. It provides an innovative way to interact with the soft tissue of the patient. So, the applications of this technology are in the medical field and are gaining popularity with better acceptabiity among masses. The students and doctors can now virtually interact with the human body and take all attention. They can gain experience with the holographic images using VR headsets. ${ }^{1,2}$

VR technology is getting popular with the advancements in hardware and software. It assists a surgeon to operate without any harm. During emergency cases, Intensive Care Unit staff can practice the procedure in limited time. It provides the best solution to study the challenging issues and their solution and is applied to build trust and to make informed decisions. It helps to sort out different neuropsychological issues for the treatment of the patient. ${ }^{3-5}$

It is a useful tool for pain management where it is helpful to reduce the pain during treatment. The applications of this technology are emerging to provide a breakthrough for the treatment of phobia. The patient can now face fear in the virtual environment without any problem. It offers high-class virtual surgery to improve the experience. Doctors can now practice in the virtual world to reduce the mistakes in surgery. It is helpful to perform successful surgery with a lesser error. This technology is a better way of improving surgical skill and solving different complex problems. ${ }^{6,7}$

\footnotetext{
* Corresponding author.

E-mail addresses: mjavaid@jmi.ac.in (M. Javaid), ahaleem@jmi.ac.in (A. Haleem).

https://scholar.google.co.in/citations? user = rfyiwvsAAAAJ\&hl=en (M. Javaid), https://scholar.google.co.in/citations? user $=4047148$ AAAAJ\&hl $=$ en $($ A. Haleem)
} 
VR is an innovative method of training for the medical group. It can be used for a range of diseases in providing adequate medical communication. In orthopaedics, it is used to identify and study the bone fracture. Young doctors can now conduct surgery digitally with step by step learning. VR glasses helps to increase the quality and performance of operation. ${ }^{8,9}$

VR is helpful for the treatment of cancer patient. The chemotherapy of the patient is easily and precisely performed. It readily undergoes the dialysis of long term illness and disabled patient. By using a VR headset, one can see the patient body and their parts digitally in different angles. ${ }^{10-12}$ This technology increases the confidence of the patient by decreasing their fear when they are using VR glasses as it provides information closer to the real-life situation. By using this technology, a heart surgeon can now check the heart rate of the patient and its changes in rate. It generates realistic images and sounds in an imaginary/virtual environment. ${ }^{13,14}$

VR technologies have distinct elements like display, optics, eye tracking, motion tracking, head tracking and audio device to provide live sound. In the medical field, it encompasses robotic surgery, surgery simulation, phobia treatment, and skills training. This technology provides better information in optimized time and cost. It is used for presenting complex and innovative ideas regarding treatment. ${ }^{15-17}$

During treatment, this technology seems useful to stop the pain of the brain. It is used to recall the memory of patient and handling different troubling situation. VR provides accurate information as happening in real conditions. It helps to detect risk to create an efficient result. This technology is helpful for the research and development processes of new diseases. A surgeon can now perform simulation-based training in a controlled environment as it guides doctors and surgeon to handle a difficult situation. ${ }^{7,18}$

In orthopaedics, it is helpful to guide and give the proper movement of fingers and arms. It is a smart way for the treatment and solution of pain. This technology educates the patient for better understanding of procedure and treatment plan as it teaches patients about the diseases, their benefits and side effects. ${ }^{19}$ This paper provides a brief about the VR and its need in the medical field. The steps performed by this technology are discussed, and significant applications are identified and discussed. Paper provides better ideas to doctors and surgeon for during complex treatment.

\section{What is virtual reality?}

Virtual reality comes from two words 'virtual' and 'reality'. The word 'virtual' means near, and 'reality' means experience as a human being. So it means it is near reality, to do specific reality emulation. VR creates a simulated environment by the applications of computer technology. It allows the user to interact in a 3D virtual world using a screen which helps to provide simulated vision, hearing and touch in the artificial 3D world. This technology has a head-mounted display component and displays a room size screen. It creates an artificial environment with software's to accept as a real environment. The main application of this technology is to create an imagined environment for game/interactive story and training in a simulated environment. ${ }^{11,20}$ This technology generates realistic images in a virtual environment to interact with virtual features. Its applications are applied currently in medical, architecture design, automobile, driving training, flight simulation and military training purpose. It is used to learn valuable information and skill with the requirement of a real one. The number of unwanted symptoms like stress injury, discomfort and other diseases is identified quickly. It provides detailed information on patient anatomy and other body parts.

\section{Need for virtual reality in the medical field}

In the medical field, this technology was introduced in the 1990s to provide adequate training and to make the surgical operation successful. Doctor, surgeon, scientists, researcher and students require better communication and coordination to create innovation in the medical field. VR is a useful technology which connects these groups to sort-out complex cases. We have to identify how it helps to provide proper training and prepare a better solution in a healthcare organization. It seems like a useful training tool in the medical field. Need to see how students can take the digital experience of complex surgery in an operating room and can help to provide proper therapy to the cancer patient.

\section{Research objectives}

The objective of this paper is to understand the capabilities of VR in medicine. Paper is to identify the status of the process of VR in the medical field. This study is to provide significant benefits of VR technologies to learn the procedure of treatment and surgery. The main objective of this paper is to identify the potential applications of VR technology in the medical field, along with a brief description.

\section{Different benefits of virtual reality in the medical field}

The today healthcare industry is adopting VR technology for better treatment of the patient, as this technology allows the learning of new skills in a safe environment. It can train new doctors and nurses to learn anatomy, the practice of operation and teaching about infection control. ${ }^{21,22}$ They can now perform a successful operation through virtual data and precisely understand the operation for complex surgery. ${ }^{23,24}$ It helps to build confidence, skill without causing any harm. Fig. 1 shows the significant contemporary benefits of virtual reality in the medical field.

VR provides a powerful diagnostic platform which opens a new door for reconstructive surgery. By the applications of this technology, one can see inside the image of the patient head digitally, and these virtual organs allow the surgeon to prepare the actual procedure to the surgeon. It reduces patient care cost and helps for the proper management of resources. It is a powerful tool to connect the physical and virtual world. ${ }^{25,26}$ New doctors and surgeon can increase their confidence level of treatment and procedure. It easily handles complicated operations with proper virtual information.

\section{Process of adoption of VR in the medical field}

The applications VR is applied to speed up the training process without any fear and risk. It is used to apply in the medical field for a wide range of disease. This technology plays a useful role to improve the performance of the medical field. ${ }^{27,28}$ It is a useful and practical technology to increase the satisfaction of trainee and the patient. This technology provides an appropriate solution using its process in the medical field, as shown in Fig. 2.

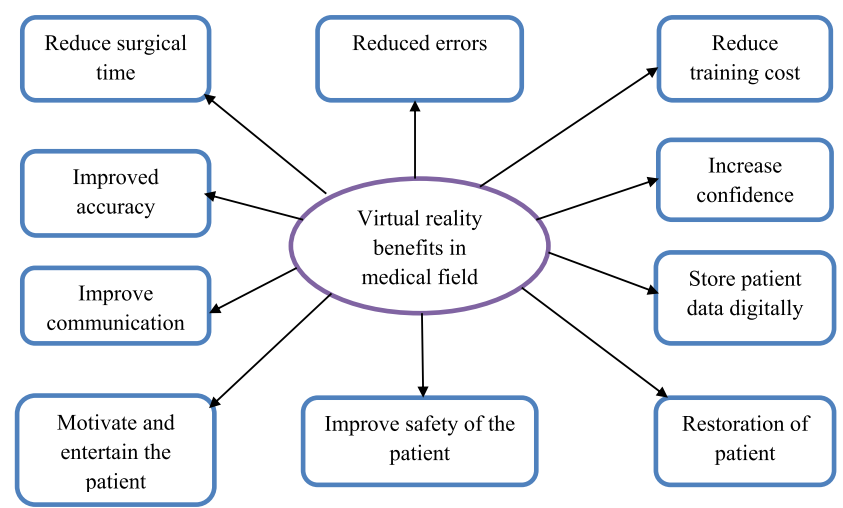

Fig. 1. Virtual reality benefits in the medical field. 


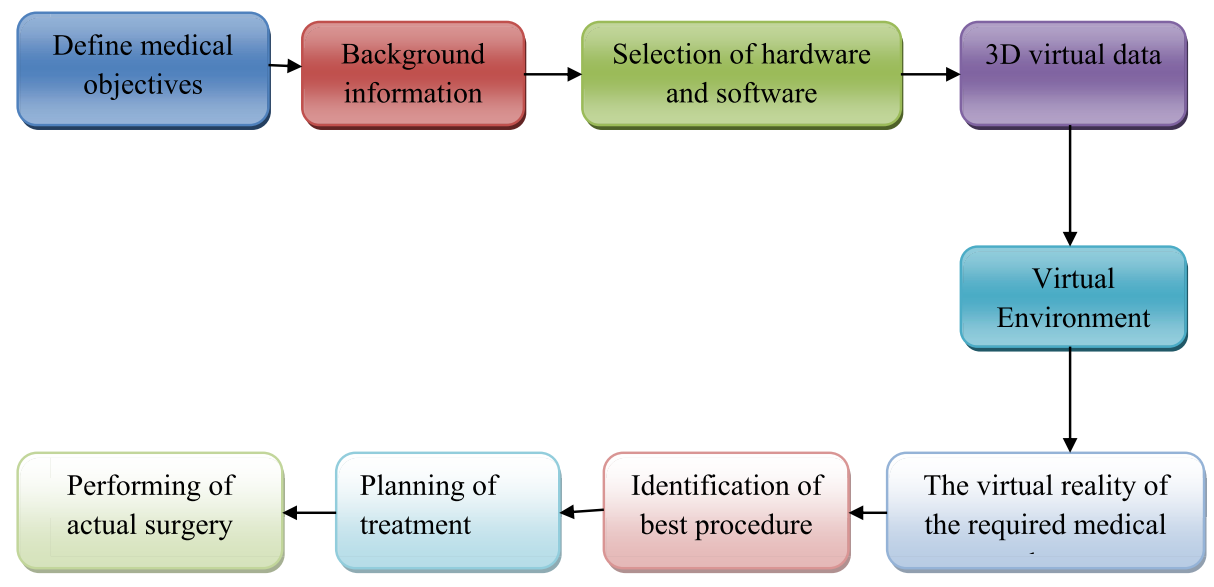

Fig. 2. Process used for VR in the medical field.

VR is an essential technology for the development process that uses customised and advanced software and hardware. First, we can define the specific objective of the required treatment and collect the background information. Different hardware and software are used to create 3D virtual data that creates a 3D virtual environment. The virtual reality of the required medical data is created and identified with the best possible procedure. This procedure is applicable to plan the treatment and finally helps to perform the actual surgery.

\section{Virtual reality applications in medical field}

The applications of this technology are in psychological therapy, medical rehabilitation, medical research and teaching; thus, students can now perform safe and controlled surgery virtually without any risk. ${ }^{20,29}$ It is helpful to learn a life-saving skill during accidental and emergency cases. VR also educate the patient for a positive lifestyle with the proper guidance of diet and exercise. Table 1 discusses the significant applications of VR in the medical field.

3D virtual reality provides a critical tool to practice on medical equipment. This technology is close to the actual procedure, which helps to perform the correct measurement of the patient body. It provides behaviours of valuable insights like changing of vital signs, varying symptoms etc. A medical professional can now easily interact with virtual patient tissues. ${ }^{74-77}$ In medical, there is a requirement of proper communication for the better treatment of the patient. ${ }^{78,79}$ It provides better visualization and measurements of the patient part by creating a cross-section in any plane. Doctors can now see the clotting of a blood vessel in the brain. Many surgeons are now performing a risky surgical procedure using virtual reality. ${ }^{80,81}$ It helps create a safe, robust and productive environment, which reduces errors in the operating room. This technology also helps cost reduction of training the medical students and improves the work environment of a physician.

\section{Discussion}

VR plays an essential role to improve the performance of the medical profession. The applications of this technology are now helping study the muscle, nerve, skin, bone and blood vessel. Medical students can now easily record a patient's information compare and analyse different medical conditions. This technology is also helpful for knee arthroscopy training which seems to be a useful tool for a better experience. It is also used to analyse and assess the skills of a surgeon. The wide range of applications of this technology is in the orthopaedics field, such as fracture fixation, hip trauma and preoperative planning. It is used for the analysis of the motion of the bone and proper placement of the implant. The immersive application of this technology is to understand the complex 3D body structure in a risk-free environment. VR is a practical approach to the pain relief of the patient. It helps to design medical therapy in a virtual environment as per symptoms of a specific patient.

VR is an emerging 3D computer technology and can be used during different medical procedure and therapy. A surgeon can now easily visualise the bone, blood vessel and other parts of the body. This technology is applied for the planning of diagnosis and reduction of risk in complex surgeries. Thus, doctors can see every procedure of treatment and other health issues in detail. VR technology can help stop the processing pain of the patient as it provides relief from stress. In cardiology, VR is applicable to perform chemotherapy treatment. It helps for the understanding of patient anatomy and planning of heart surgery in a precise manner. It generates a $3 \mathrm{D}$ virtual world for productive interaction. The medical field uses VR to relieve pain during medical and surgical procedures. This paper fulfils the required objectives. The clear understanding of VR in the medical field is discussed with its significant benefits. The process steps in the medical field during its implementation is shown and discussed. Finally, its potential applications are identified and discussed.

\section{Limitations}

The main limitation of this technology is its commercial implementation in the medical field due to its high cost. VR is time-consuming during the treatment and needs extensive software support and hardware support. It requires extra cost for high-resolution patient data. VR images require ample file space to stored data. Currently, this technology is not useful to identify the symptoms of new diseases. It is limited only to understand particular cases and requires proper motion of the body part for the proper treatment. It is limited for the demonstration, and VR headset covers limited areas and body movement of the patient. However, extensive research and its integration with other technologies are going to make this quite helpful to the masses.

\section{Future scope}

In future, the applications of VR will become somewhat familiar in healthcare. Doctors and surgeon can perform any complicated operations precisely and in a safe manner. The surgical team can see the soft and hard tissue inside the patient body to plan a successful procedure. It will become sophisticated devices and powerful tool which create a high-quality visualization. The medical profession can enhance knowledge, skill, habits and other required disciplines. This technology will apply for the construction of building, industry and hospital with optimized design. It will become more intelligent in the upcoming years, which help to introduce all medical processes in the digital world. VR holds promising techniques to save and improve the life of 
Table 1

Virtual reality applications in the medical field.

\begin{tabular}{|c|c|c|c|}
\hline S No & Applications & Description & References \\
\hline 1 & Virtual surgery & $\begin{array}{l}\text { - VR is used to provide virtual surgery which is helpful to reduce time and } \\
\text { risk } \\
\text { - Used for telesurgery for the surgeon at different locations } \\
\text { Helpful to measure and analyse pressure required to perform the } \\
\text { procedure } \\
\text { - It is the best technique to simulate surgery procedure } \\
\text { Provides a clear picture which helps to better plan and practice }\end{array}$ & $\begin{array}{l}\text { Marco et al., } 2013^{30} \text {; Diemer et al., } 2015^{31} \text {; Lin et al., } \\
2019^{32}\end{array}$ \\
\hline 2 & Planning of operation & $\begin{array}{l}\text { - By the applications of virtual 3D models, the surgeon can successfully plan } \\
\text { the operation to complete it successfully } \\
\text { - It provides a better way of communication for the medical profession } \\
\text { - During operation, this technology develop a precise image of the patient } \\
\text { - To interact with surgical treatment, the surgeon interacts with the latest } \\
\text { virtual glasses in a 3D environment }\end{array}$ & Botella et al., $2015^{33}$; Li et al., $2017^{34}$; Park et al., $2019^{35}$ \\
\hline 3 & Diagnosis & $\begin{array}{l}\text { Powerful diagnosis tool for accurate diagnosis carried out by doctors and } \\
\text { physicians } \\
\text { - It eliminates the requirement of computerized tomography (CT)/magnetic } \\
\text { resonance imaging (MRI) scan } \\
\text { - Quickly identifies the signs and symptom of diseases } \\
\text { - Collect the information regarding patient for proper diagnosis }\end{array}$ & $\begin{array}{l}\text { Tyrrell et al., } 2017^{36} \text {; Cooper et al., } 2018^{37} \\
\text { HajesmaeelGohari et al., } 2019^{38}\end{array}$ \\
\hline 4 & Physical therapy & $\begin{array}{l}\text { - By using this technology, there is a profound change in the way people do } \\
\text { the exercise } \\
\text { - It plays a significant role in physical therapy subject to a proper routine } \\
\text { exercise } \\
\text { - VR assists therapy achieves better result during practical implementation } \\
\text { - Helpful for the treatment of burn victims with minor pain } \\
\text { - Helps quick sorting of different cognitive issues in a comfortable and safe } \\
\text { manner }\end{array}$ & $\begin{array}{l}\text { Rothbaum et al., } 2010^{39} \text {; Parsons et al., } 2017^{40} \text {; Beidel } \\
\text { et al., } 2019^{41}\end{array}$ \\
\hline 5 & Education and training & $\begin{array}{l}\text { - Helpful in medical education and training by creating the best possible } \\
\text { learning program }\end{array}$ & Bun et al., $2017^{42}$; Drewett et al., $2019^{43}$ \\
\hline
\end{tabular}

- It is helpful to plan and practise a complicated surgical procedure with minimum risk

- Enhanced students understanding of age-related problems and diseases

- Introduced an innovative way of teaching and learning process of medical students

6 Treatment of mental illness

Better treatment of limb pain

Learning of surgical technique

Digital storage of patient data

10 Identification of breathing problems

11 Improve the efficiency of psychotherapy

12 Reduce Depression

Track body movement
- This technology is used to change the way of exposure therapy which is helpful for different types of mental illness

- Provides a low-cost treatment with a lesser risk of life

- VR provides social interaction in virtual characters which is further helpful to develop a life skill

- Helpful for the therapy of the patient suffering the mental health issues

- Creates a virtual limb to analyse the pain of the patient body

- Provide a better experience for the movement of missing limb

- It helps to increase patient confidence to learn and control the cause of pain

- VR technology enters in the medical field to train young doctors

- Provides a personal approach to each patient

- This technology enables physicians, doctors, nurses, surgeon and other medical professionals for better interaction using simulation technique

- Interacts patient in a 3D environment to enhance knowledge and experience

- Doctors can perform virtual surgery which makes the actual procedure successful

- Data is stored in digital format which is helpful for future treatment

- VR technology has more diverse applications to reduce the paperwork

- It is helpful to solve complex problems and treatment of different diseases digitally

- This data is also used for the research and development process of diseases

- It quickly identifies the breathing problem of the patient and further helpful for its treatment

- Used to balance the rate of heart and blood pressure

- A patient can watch virtual exercises to sort out this problem

- Seems to an excellent tool for psychotherapy to improve the efficiency

- It has great potential for curing of various other mental diseases

- Useful for regular personal interaction which is helpful to change the behaviours and sort-out the required problem

- By using this technology, doctors and researcher proves that there is a reduction of depression in young people

- The applications of this technology improve the quality of life of adult and children

- VR changes the mind and brain of the person having depression

- VR is a useful tool which is helpful to track body movement of the patient

- Provides an interactive way for therapy exercise of the patient

- This technology produced excellent exposure as done in real life

- Quickly analyse the motion of the bones
Riva et al., 2011 ${ }^{44}$; Valmaggia et al., $2016^{45}$; Chirico et al., $2016^{46}$; Mubin et al., $2019^{47}$

Dascal et al., 2017 ${ }^{48}$; Tashjian et al., 2017 ${ }^{49}$; Samadbeik et al., 2018 ${ }^{50}$; Parham et al., 201951

Maples-Keller et al., 2017 ${ }^{52}$; Du Sert et al., 2018 ${ }^{53}$; Gadelha, $2018^{54}$

McIntosh et al., 201455; Flores et al., 2018 56 ; SánchezCabrero et al., $2019^{57}$

Russell, 2014 ${ }^{58}$; Parsons, 2015 ${ }^{59}$; De Luca et al., $2019^{60}$

Bergeron et al., 2015 ${ }^{61}$; Tromp et al., 2018 ${ }^{62}$; MatamalaGomez et al., $2019^{63}$

Biffi et al., 2017 ${ }^{64}$; Yildirim et al., $2018^{65}$; Norouzi et al., $2019^{66}$

Ryu et al., 2014 ${ }^{67}$; Faric et al., 2019 ${ }^{68}$; Ventola, $2019^{69}$; Haleem and Javaid, $2019^{70}$ 
Table 1 (continued)

\begin{tabular}{|c|c|c|c|}
\hline S No & Applications & Description & References \\
\hline 14 & Reduce trauma pain & $\begin{array}{l}\text { - This technology applies to reduced pain when the patient interact virtually } \\
\text { - Patients can practice virtually exercises in a safe environment } \\
\text { - Successfully recover from trauma to perform the cognitive function }\end{array}$ & $\begin{array}{l}\text { Vergara et al., } 2017^{27} \text {; Chan et al., } 2018^{71} \text {; Peeters, } \\
2019^{72} \text {; Chen et al., } 2018^{73}\end{array}$ \\
\hline
\end{tabular}

the patient. It quickly addresses any deficiency regarding the skill of the surgeon. This immersive technology addresses training in the operating room environment anytime and anywhere. With the help of this technology, one can easily watch the correct and incorrect status of the disease. It guides doctors and nurse regarding the biological mechanism of the body. This technology creates realistic and accurate simulations in a virtual world.

\section{Conclusion}

Virtual reality brings new possibilities and facilitates healthcare with a positive experience for the treatment of the patient by creating a virtual 3D environment. It gives a better perception of the surrounding environment. This technology has diverse applications in neuroscience, psychology, physical and occupational therapy and other intervention approaches and has the potential for the treatment of stress-related disorders. In the medical field, this technological revolution seems the right solution, which can allow immersing the situations. It can reduce therapist consultation duration. This technology is now useful for taking up unique patient cases and challenges. The applications of this technology are explored rapidly from the past few years to make valuable achievements. Thus to fulfil these requirements, VR technology is successfully implemented in the medical field to create efficient treatment outcomes.VR seems effective to lower the cost of the entire treatment process. By using this technology, the patient focuses on realworld and gets relieved from overall stress. It provides experience to the human brain by offering virtual motion and experience. For stress management, this technology provides an effective and better solution which enhances patient and creates a positive effect to save the life of the patient.

\section{Declaration of competing interest}

None.

\section{References}

1. Bouchard S, Dumoulin S, Robillard G, et al. Virtual reality compared with exposure in the treatment of social anxiety disorder: a three-arm randomised controlled trial. $\mathrm{Br} \mathrm{J}$ Psychiatry. 2017;210(4):276-283

2. Birckhead B, Khalil C, Liu X, et al. Recommendations for methodology of virtual reality clinical trials in health care by an international working group: iterative study. JMIRMent Health. 2019;6(1):e11973https://doi.org/10.2196/11973.

3. Bordnick PS, Carter BL, Traylor AC. What virtual reality research in addictions can tell us about the future of obesity assessment and treatment. J Diabetes Sci Technol. 2011;5(2):265-271.

4. Ghai S, Ghai I. Virtual reality enhances gait in cerebral palsy: a training dose-response meta-analysis. Front Neurol. 2019;10:236. https://doi.org/10.3389/fneur. 2019.00236.

5. Haleem A, Javaid M. 3D scanning applications in medical field: a literature-based review. Clin Epidemiol Global Health. 2019;7(2):199-210.

6. Heyselaar E, Hagoort P, Segaert K. How social opinion influences syntactic processing - an investigation using virtual reality. PLoS One. 2017;12(4):e0174405.

7. Coyne L, Merritt TA, Parmentier BL, Sharpton RA, Takemoto JK. The past, present, and future of virtual reality in pharmacy education. Am J Pharmaceut Educ. 2019;83(3):7456. https://doi.org/10.5688/ajpe7456.

8. Malbos E, Rapee RM, Kavakli M. A controlled study of agoraphobia and the independent effect of virtual reality exposure therapy. Aust N Z J Psychiatr. 2013:47:160-168.

9. Khan R, Plahouras J, Johnston BC, Scaffidi MA, Grover SC, Walsh CM. Virtual reality simulation training for health professions trainees in gastrointestinal endoscopy. Cochrane Database Syst Rev. 2018;8(8) CD008237.

10. Yoo JW, Lee DR, Sim YJ, You JH, Kim CJ. Effects of innovative virtual reality game and EMG biofeedback on neuromotor control in cerebral palsy. Bio Med Mater Eng.
2014;24:3613-3618

11. Gold JI, Mahrer NE. Is virtual reality ready for prime time in the medical space? A randomized control trial of pediatric virtual reality for acute procedural pain management. J Pediatr Psychol. 2018;43:266-275.

12. Javaid M, Haleem A, Kumar L. Current status and applications of 3D scanning in dentistry. Clin Epidemiol Global Health. 2019;7(2):179-185.

13. Lee M, Billinghurst M, Baek W, Green R, Woo W. A usability study of multimodal input in an augmented reality environment. Virtual Real. 2013;17(4):293-305.

14. Peskin M, Wyka K, Cukor J, et al. The relationship between posttraumatic and depressive symptoms during virtual reality exposure therapy with a cognitive enhancer. J Anxiety Disord. 2019;61:82-88.

15. Javaid M, Haleem A. Additive manufacturing applications in medical cases: a literature-based review. Alexandria J Med. 2018;54(4):411-422.

16. Crossley R, Liebig T, Holtmannspoetter M, et al. Validation studies of virtual reality simulation performance metrics for mechanical thrombectomy in ischemic stroke. $J$ Neurointerventional Surg. 2019;11(8):775-780.

17. Javaid M, Haleem A. Industry 4.0 applications in medical field: a brief review. Curr Med Res Prac. 2019;9(3):102-109.

18. Subramanian SK, Lourenço CB, Chilingaryan G, Sveistrup H, Levin MF. Arm motor recovery using a virtual reality intervention in chronic stroke: randomized control trial. Neurorehabilitation Neural Repair. 2013;27(1):13-23.

19. Huygelier H, Schraepen B, van Ee R, VandenAbeele V, Gillebert CR. Acceptance of immersive head-mounted virtual reality in older adults. Sci Rep. 2019;9(1):4519. https://doi.org/10.1038/s41598-019-41200-6.

20. Haleem A, Javaid M, Vaishya R, Khan IH. Virtual reality applications in orthopaedics. J Orthop Allied Sci. 2019. https://doi.org/10.4103/joas.joas_37_19.

21. Gatica-Rojas V, Méndez-Rebolledo G. Virtual reality interface devices in the reorganization of neural networks in the brain of patients with neurological diseases. Neural Regen Res. 2014;9(8):888-896.

22. Haleem A, Javaid M. Role of CT and MRI in the design and development of orthopaedic model using additive manufacturing. J Clin Orthop Trauma. 2018;9(3):213-217.

23. Porras DC, Siemonsma P, Inzelberg R, Zeilig G, Plotnik M. Advantages of virtual reality in the rehabilitation of balance and gait: systematic review. Neurology. 2018;90:1017-1025.

24. Javaid M, Haleem A. Additive manufacturing applications in orthopaedics: a review. J Clin Orthop Trauma. 2018;9(3):202-206.

25. Lin MT, Wang J, Kuo H, Luo Y. A study on the effect of virtual reality 3D exploratory education on students' creativity and leadership. Eurasia J Math Sci Technol Educ. 2017;13(7):3151-3161

26. Haleem A, Javaid M. Additive manufacturing applications in industry 4.0: a review. $J$ Ind Integr Manag. 2019. https://doi.org/10.1142/S2424862219300011.

27. Vergara D, Rubio MP, Lorenzo M. On the design of virtual reality learning environments in engineering. Multimodal Technol Interact. 2017;1:11. https://doi.org/ $10.3390 / \mathrm{mti} 1020011$.

28. Zhang JF, Paciorkowski AR, Craig PA, Cui F. Bio VR: a platform for virtual reality, assisted biological data integration and visualization. BMC Bioinf. 2019;20(1):78. https://doi.org/10.1186/s12859-019-2666-z.

29. Pan $X$, Hamilton AFDC. Why and how to use virtual reality to study human social interaction: the challenges of exploring a new research landscape. $\mathrm{Br} J$ Psychol. 2018;109:395-417.

30. Marco JH, Perpina C, Botella C. Effectiveness of cognitive-behavioural therapy supported by virtual reality in the treatment of body image in eating disorders: oneyear follow-up. Psychiatry Res. 2013;209:619-625.

31. Diemer JE, Alpers GW, Peperkorn HM, Shiban Y, Mühlberger A. The impact of perception and presence on emotional reactions: a review of research in virtual reality. Front Psychol. 2015;6:26. https://doi.org/10.3389/fpsyg.2015.00026.

32. Lin HT, Li YI, Hu WP, Huang CC, Du YC. A scoping review of the efficacy of virtual reality and exergaming on patients of musculoskeletal system disorder. $J$ Clin Med. 2019;8(6):791. https://doi.org/10.3390/jcm8060791.

33. Botella C, Serrano B, Baños RM, Garcia-Palacios A. Virtual reality exposure-based therapy for the treatment of post-traumatic stress disorder: a review of its efficacy, the adequacy of the treatment protocol, and its acceptability. Neuropsychiatric Dis Treat. 2015;11:2533-2545.

34. Li L, Yu F, Shi D, et al. Application of virtual reality technology in clinical medicine. Am J Transl Res. 2017;9(9):3867-3880.

35. Park MJ, Kim DJ, Lee U, Na EJ, Jeon HJ. A literature overview of virtual reality (VR) in treatment of psychiatric disorders: recent advances and limitations. Front Psychiatry. 2019;10:505. https://doi.org/10.3389/fpsyt.2019.00505.

36. Tyrrell R, Sarig-Bahat H, Williams K, Williams G, Treleaven J. Simulator sickness in patients with neck pain and vestibular pathology during virtual reality tasks. Virtual Real. 2017;22(3):211-219.

37. Cooper N, Milella F, Pinto C, Cant I, White M, Meyer G. The effects of substitute multisensory feedback on task performance and the sense of presence in a virtual reality environment. PLoS One. 2018;13(2):e0191846https://doi.org/10.1371/ journal.pone.0191846. 
38. HajesmaeelGohari S, Gozali E, NiakanKalhori SR. Virtual reality applications for chronic conditions management: a review. Med J Islam Repub Iran. 2019;33:67. https://doi.org/10.34171/mjiri.33.67.

39. Rothbaum BO, Rizzo AS, Difede J. Virtual reality exposure therapy for combat-related posttraumatic stress disorder. Ann N Y Acad Sci. 2010;1208:126-132.

40. Parsons TD, Gaggioli A, Riva G. Virtual reality for research in social neuroscience. Brain Sci. 2017;7(4):42. https://doi.org/10.3390/brainsci7040042.

41. Beidel DC, Frueh BC, Neer SM, et al. Trauma management therapy with virtualreality augmented exposure therapy for combat-related PTSD: a randomized controlled trial. J Anxiety Disord. 2019;61:64-74.

42. Bun PK, Wichniarek R, Górski F, Grajewski D, Zawadzki P. Possibilities and determinants of using low-cost devices in virtual education applications. Eurasia J Math Sci Technol Educ. 2017;13(2):381-394.

43. Drewett O, Hann G, Gillies M, et al. A discussion of the use of virtual reality for training healthcare practitioners to recognize child protection issues. Front Public Health. 2019;7:255. https://doi.org/10.3389/fpubh.2019.00255.

44. Riva G. The key to unlocking the virtual body: virtual reality in the treatment of obesity and eating disorders. J Diabetes Sci Technol. 2011;5:283-292.

45. ValmaggiaLR Latif L, Kempton MJ, Rus-Calafell M. Virtual reality in the psychological treatment for mental health problems: an systematic review of recent evidence. Psychiatry Res. 2016;236:189-195.

46. Chirico A, Lucidi F, De Laurentiis M, Milanese C, Napoli A, Giordano A. Virtual reality in health system: beyond entertainment. A mini-review on the efficacy of VR during cancer treatment. J Cell Physiol. 2016;231(2):275-287.

47. Mubin O, Alnajjar F, Jishtu N, Alsinglawi B, Al Mahmud A. Exoskeletons with virtual reality, augmented reality, and gamification for stroke patients' rehabilitation: systematic review, JMIRRehabil Assist Technol. 2019;6(2):e12010.

48. Dascal J, Reid M, IsHak WW, et al. Virtual reality and medical inpatients: a systematic review of randomized, controlled trials. Innov Clin Neurosci. 2017;14(12):14-21

49. Tashjian VC, Mosadeghi S, Howard AR, et al. Virtual reality for management of pain in hospitalized patients: results of a controlled trial. JMIRMent Health. 2017;4(1):e9. https://doi.org/10.2196/mental.7387.

50. Samadbeik M, Yaaghobi D, Bastani P, Abhari S, Rezaee R, Garavand A. The applications of virtual reality technology in medical groups teaching. J Adv Med Educ Prof. 2018;6(3):123-129

51. Parham G, Bing EG, Cuevas A, et al. Creating a low-cost virtual reality surgical simulation to increase surgical oncology capacity and capability. E Cancer Med Sci. 2019;13:910. https://doi.org/10.3332/ecancer.2019.910.

52. Maples-Keller JL, Bunnell BE, Kim S, Rothbaum BO. The use of virtual reality technology in the treatment of anxiety and other psychiatric disorders. Harv Rev Psychiatry. 2017;25(3):103-113.

53. Du Sert OP, Potvin S, Lipp O, et al. Virtual reality therapy for refractory auditory verbal hallucinations in schizophrenia: a pilot clinical trial. Schizophr Res. 2018;197:176-181.

54. Gadelha R. Revolutionizing education: the promise of virtual reality. Child Educ. 2018;94(1):40-43.

55. McIntosh KS, Gregor JC, Khanna NV. Computer-based virtual reality colonoscopy simulation improves patient-based colonoscopy performance. Can. J. Gastroenterol. Hepatol. 2014;28(4) 203-6.

56. Flores A, Linehan MM, Todd SR, Hoffman HG. The use of virtual reality to facilitate mindfulness skills training in dialectical behavioral therapy for spinal cord injury: a case study. Front Psychol. 2018;9:531. https://doi.org/10.3389/fpsyg.2018.00531.

57. Sánchez-Cabrero R, Costa-Román Ó, Pericacho-Gómez FJ, Novillo-López MÁ, Arigita-García A, Barrientos-Fernández A. Early virtual reality adopters in Spain: sociodemographic profile and interest in the use of virtual reality as a learning tool. Heliyon. 2019;5(3):e01338https://doi.org/10.1016/j.heliyon.2019.e01338.

58. Russell MEB, Hoffman B, Stromberg S, Carlson CR. Use of controlled diaphragmatic breathing for the management of motion sickness in a virtual reality environment. Appl Psychophysiol Biofeedback. 2014;39(3-4):269-277.

59. Parsons TD. Virtual reality for enhanced ecological validity and experimental control in the clinical, affective and social neurosciences. Front Hum Neurosci. 2015;9:660. https://doi.org/10.3389/fnhum.2015.00660

60. De Luca R, Manuli A, De Domenico C, et al. Improving neuropsychiatric symptoms following stroke using virtual reality: a case report. Medicine (Baltim). 2019;98(19):e15236

61. Bergeron M, Lortie CL, Guitton MJ. Use of virtual reality tools for vestibular disorder rehabilitation: a comprehensive analysis. Adv Met Med. 2015;2015. https://doi.org/ 10.1155/2015/916735 916735

62. Tromp J, Peeters D, Meyer AS, Hagoort P. The combined use of virtual reality and EEG to study language processing in naturalistic environments. Behav Res Methods. 2018;50(2):862-869.

63. Matamala-Gomez M, Donegan T, Bottiroli S, Sandrini G, Sanchez-Vives MV, Tassorelli C. Immersive virtual reality and virtual embodiment for pain relief. Front Hum Neurosci. 2019;13:279. https://doi.org/10.3389/fnhum.2019.00279.

64. Biffi E, Beretta E, Cesareo A, et al. An immersive virtual reality platform to enhance walking ability of children with acquired brain injuries. Methods Inf Med. 2017;56:119-126.

65. Yildirim G, Elban M, Yildirim S. Analysis of use of virtual reality technologies in history education: a case study. Asian J. Educ. Train. 2018;4:62-69.

66. Norouzi N, Bölling L, Bruder G, Welch G. Augmented rotations in virtual reality for users with a reduced range of head movement. J Rehabil Assist Technol Eng. 2019. https://doi.org/10.1177/2055668319841309.

67. Ryu JH, Park JW, Nahm FS, et al. The effect of gamification through a virtual reality on preoperative anxiety in pediatric patients undergoing general anesthesia: a prospective, randomized, and controlled trial. J Clin Med. 2018;7(9):284. https://doi. org/10.3390/jcm7090284.

68. Faric N, Yorke E, Varnes L, et al. Younger adolescents' perceptions of physical activity, exergaming, and virtual reality: qualitative intervention development study. JMIR Serious Games. 2019;7(2):e11960https://doi.org/10.2196/11960.

69. Ventola CL. Virtual reality in pharmacy: opportunities for clinical, research, and educational applications. PT. 2019;44(5):267-276.

70. Haleem A, Javaid M. Industry 5.0 and its applications in orthopaedics. J Clin Orthop Trauma. 2019;10:807-808.

71. Chan E, Foster S, Sambell R, Leong P. Clinical efficacy of virtual reality for acute procedural pain management: a systematic review and meta-analysis. PLoS One. 2018;13:e0200987.

72. Peeters D. Virtual reality: a game-changing method for the language sciences Psychon Bull Rev, 2019;26(3):894-900.

73. Chen Y, Fanchiang HD, Howard A. Effectiveness of virtual reality in children with cerebral palsy: a systematic review and meta-analysis of randomized controlled trials. Phys Ther. 2018;98:63-77.

74. Won AS, Tataru CA, Cojocaru CM, et al. Two virtual reality pilot studies for the treatment of pediatric CRPS. Pain Med. 2015;16:1644-1647.

75. Norr AM, Smolenski DJ, Reger GM. Effects of prolonged exposure and virtual reality exposure on suicidal ideation in active duty soldiers: an examination of potential mechanisms. J Psychiatr Res. 2018;103:69-74.

76. Tussyadiah IP, Wang D, Jung TH, tom-Dieck MC. Virtual reality, presence, and attitude change: empirical evidence from tourism. Tour Manag. 2018;66:140-154.

77. Haleem A, Javaid M. Industry 5.0 and its expected applications in medical field. Curr Med Res Prac. 2019;9(4):167-169

78. Awasthi S, Verma T, Agarwal M, Singh JV, Srivastava NM, Nichterd M. Developing effective health communication messages for community-acquired pneumonia in children under five years of age: a rural North Indian qualitative study. Clin Epidemiol Global Health. 2017;5:107-116.

79. Leder J, Horlitz T, Puschmann P, Wittstock V, Schütz A. Comparing immersive virtual reality and powerpoint as methods for delivering safety training: impacts on risk perception, learning, and decision making. Saf Sci. 2019;111:271-286.

80. Haleem A, Javaid M, Khan IH. Virtual reality (VR) applications in dentistry: an innovative technology to embrace. Indian J Dent Res. 2019. https://doi.org/10.4103/ ijdr.IJDR_501_19.

81. Pizzoli SFM, Triberti S, Monzani D, Alcañiz Raya ML, Pravettoni G. User-centered virtual reality for promoting relaxation: an innovative approach. Front Psychol. 2019;10:479. https://doi.org/10.3389/fpsyg.2019.00479. 